\title{
Separating the effects of physical and biological aspects of mussel beds on their associated assemblages
}

\author{
M. G. Palomo ${ }^{1,2, *}$, J. People ${ }^{1}$, M. G. Chapman ${ }^{1}$, A. J. Underwood ${ }^{1}$ \\ ${ }^{1}$ Marine Ecology Laboratories A11, Centre for Research on Ecological Impacts of Coastal Cities, University of Sydney, \\ New South Wales 2006, Australia \\ ${ }^{2}$ Present address: Museo Argentino Ciencias Naturales Bernardino Rivadavia, Av. A. Gallardo 470, 3er Piso, Lab 57, \\ C1405DJR, Buenos Aires, Argentina
}

\begin{abstract}
Mussels provide habitat for diverse assemblages and have a major influence on local biodiversity. Organisms may be associated with the physical structure of the mussels or mussel beds, with biological characteristics of the shells of the mussels or with the living mussels themselves. We examined colonisation of experimentally-built patches of live mussels, dead mussel shells and resin mimics to test models regarding these cues. The sessile assemblage on the valves of the mussels and the mobile assemblage living in the spaces among the mussels were separately examined to evaluate whether they respond in the same way. In addition, the experiment incorporated 2 levels of clumping of mussels to represent sparse and clumped mussel beds after 5 and 9 mo of deployment of the patches. With few exceptions, there was no effect of the types of mussels provided; similar species and abundances were found on and among live mussels, dead shells and resin mimics after both time periods. Therefore, it appears that mussel beds act predominantly as physical habitats for these fauna. In contrast, the degree of clumping of mussels in a patch had major effects. After 5 mo, barnacles and spirorbid polychaetes had greater covers on the valves of sparsely packed mussels than on clumped mussels. The opposite pattern was shown by spirorbids and serpulids after 9 mo, although barnacles retained their original pattern. Some mobile taxa showed greater abundances in clumped than sparse patches, but these differences largely disappeared when the data were corrected for the number of mussels. Therefore, mobile taxa appeared to respond directly to the number of mussels in a patch; more mussels created more habitat. This was not the case for the sessile assemblage, where mussel shells in sparse beds appeared to provide different habitat from those in clumped beds.
\end{abstract}

KEY WORDS: Biodiversity $\cdot$ Colonisation $\cdot$ Habitat $\cdot$ Invertebrate assemblage $\cdot$ Mussels

\section{INTRODUCTION}

Many organisms, including intertidal species, such as algae (Kelaher 2002), polychaete worms (Khaitov et al. 1999) and barnacles (Reimer 1976), form biogenic habitats by providing a structure that can act as a surface for attachment and/or shelter for other organisms. These habitats vary in structure according to the density, type, or size of the organisms that form them. Differences in physical structure can influence the amount of light, humidity, and shelter within a habitat (Iwasaki 1995). In addition, dense configurations of marine organisms can retain more sediment than sparse configurations (Gibbons 1988), which can also affect the assemblages that inhabit these areas.

The habitat provided by habitat-forming organisms has a range of biological properties associated with occupying a living substratum, e.g. feeding and production of waste (Seed \& Suchanek 1992). To separate the effects of biological properties from the physical 
properties of habitats, studies have used artificial materials to mimic the physical properties of biogenic habitats (Dean 1981, Crooks \& Khim 1999, Kelaher 2002). Comparisons of such mimics to naturally occurring biogenic habitats have shown mixed results. In some cases, the distributions and abundances of organisms inhabiting artificial habitats differed from those in the natural habitat, implying that mostly biological factors affected the assemblage (Ricciardi et al. 1997). In other cases, few differences occurred between natural and artificial habitats, implying that the physical structure of the habitat was more important than its biological characteristics (Crooks \& Khim 1999, Kelaher 2002). However, few of these studies used mimics that closely resembled the physical structure of the biogenic habitat, because it was either difficult to mimic (Kelaher 2002), or because the hypotheses being tested did not require that mimics closely resemble the natural habitat (e.g. Smith \& Rule 2002). Few of these studies were adequately replicated or had appropriate controls for the manipulations (Gwyther \& Fairweather 2002, Rule \& Smith 2005). Even fewer compared assemblages inhabiting mimics to those occurring naturally to test whether similar assemblages developed in each habitat (but see Kelaher 2002), or considered differences in physical and biological properties of habitats (but see Gwyther \& Fairweather 2002).

Mussels form clumps, or beds, that provide a biogenic habitat for a range of organisms, including algae, ascidians, amphipods, isopods and gastropods (e.g. Tsuchiya \& Nishihira 1985, 1986, Seed \& Suchanek 1992, Chapman et al. 2005). However, it is not clear what properties of mussel beds influence the development of the associated assemblage. Various microhabitats are found in mussel beds. Their shells provide substrata for sessile organisms, such as algae, ascidians and barnacles (Seed \& Suchanek 1992), or mobile animals, such as limpets. The byssal threads and the spaces between the mussels are inhabited by mobile organisms, such as crabs, errant polychaetes, amphipods and bivalves (Seed \& Suchanek 1992). The sediment, waste products and shell fragments that settle within the bed are inhabited by infauna, such as polychaetes and sipunculids (Jaramillo et al. 1992, Seed \& Suchanek 1992).

The physical properties of mussel beds, such as differences in the size, age (Tsuchiya \& Nishihira 1986), number or density of mussels (Stewart et al. 1998), thickness of the bed (Suchanek 1985), number of layers of mussels (Tsuchiya \& Nishihira 1986) or size of a patch (Tsuchiya \& Nishihira 1985) can increase or decrease the abundances and types of organisms that inhabit them. Older mussels, for example, are inhabited by more species than are younger mussels
(Tsuchiya \& Nishihira 1986). However, the physical effects of mussels on water flow and shelter from waves have not been separated from biological properties (e.g. the composition of the shell) or from influences due to the mussels feeding and associated deposition of pseudofaeces, faeces, nutrients and sediment.

The relative importance or interactions between biological and physical influences of mussels probably depends on their arrangements in clumps, particularly their densities, numbers of layers and degree of clumpedness. Separation of the above factors is very difficult and probably impossible in some cases, because many of the factors are tightly correlated. For example, thickness of the mussel bed may be related to the number of layers within the mussel bed or to the size of mussels, which may, in turn, be related to the age of the mussel bed. Attributing causality of differences in assemblages to one particular factor is therefore not possible without complex manipulative experiments to unravel confounded factors.

Experimental attempts have been made to interpret various roles provided by mussels in terms of protection from waves, provision of complex 3-dimensional habitat (Dean 1981) or creation of nutrient-rich sediments (Kautsky \& Evans 1987) for marine (Suchanek 1985, Tsuchiya \& Nishihira 1986) and freshwater mussels (Wisenden \& Bailey 1995, Ricciardi et al. 1997). In many of these studies, only some aspects of the physical and biological features of the mussels were investigated, and in only a few cases, assemblages in experimental clumps of mussels were compared to those among natural mussels (Ricciardi et al. 1997).

In this study, influences of potentially important physical and biological features of mussel beds on associated assemblages were examined experimentally using Mytilus galloprovincialis. The characteristics of the shells and the clumping of the mussels were examined using patches of mussels constructed of artificial, dead or live mussels. If the biological activity of mussels affects the associated assemblage, live mussels should be inhabited by different assemblages from those found among dead mussels, which would be similar to assemblages in artificial mussels. However, if it is only the characteristics of the shell that affect these assemblages, then live mussels would have similar assemblages to those found among dead mussels and different assemblages from those developing among artificial mussels. If the physical characteristics of mussels (e.g. in reducing wave forces or trapping sediment) are the major influences, then live, dead and artificial mussels would be inhabited by similar assemblages. If there is a combined effect of any of the above characteristics on assemblages, then live, dead and artificial mussels would each be inhabited by different assemblages. 
If the structure of mussel beds affects the associated assemblage, clumped and sparse mussel beds should develop different assemblages. We therefore used sparse and clumped experimental patches of all 3 treatments. Finally, assemblages in the experimental patches were compared to those in naturally occurring beds to test the extent to which experimental patches were representative of natural habitat. Organisms living on mussels (mostly sessile organisms) and those living among mussels (mostly mobile organisms) were considered separately because it was proposed that physical structure, attributes of live mussels and other biological properties of the habitat would affect these groups differently.

\section{MATERIALS AND METHODS}

The experiments were conducted on a vertical sandstone seawall at Illoura Reserve, Balmain, an urbanised area inside Sydney Harbour, New South Wales, Australia. The wall was approximately $250 \mathrm{~m}$ long $\times 2 \mathrm{~m}$ high with many patches of densely clumped mussels. The mussels occurred at mid to low tidal height (between 0.6 and $1.1 \mathrm{~m}$ above Indian Low Water Spring tide, the local datum). Live Mytilus galloprovincialis used to construct the experimental beds were collected from a nearby seawall at Blues Point, Sydney Harbour, in order to minimise disturbance in the experimental site. The mussels were taken to the laboratory and kept in running seawater for $4 \mathrm{~d}$. To prepare mussels for the experiment, their byssal threads were cut, and the mussels were individually scraped clean of all attached organisms.

Construction of experimental patches. Three types of experimental patches of mussels were constructed. The first used live mussels, the second used mussel shells with the animals removed and the third used artificially constructed mussels. For each type of patch, there were 2 different clumping densities: clumped (120 mussels $225 \mathrm{~cm}^{-2}$ ) and sparse (20 mussels $225 \mathrm{~cm}^{-2}$ ). These densities represent high and low densities found naturally at similar sites in Sydney Harbour. The shell lengths in a sample of mussels collected from Illoura Reserve were used as a guide for construction of the mussel beds. The natural beds had $14 \%$ of mussels with shells 1 to $1.95 \mathrm{~cm}$ long, $43 \%$ with shells 2 to $2.95 \mathrm{~cm}$ long, $35 \%$ with shells 3 to $3.95 \mathrm{~cm}$ long, $7 \%$ with shells 4 to $4.95 \mathrm{~cm}$ long and $1 \%$ with shells 5 to $6 \mathrm{~cm}$ long. The experimental patches were therefore made using this size distribution. Only mussels larger than approximately $1 \mathrm{~cm}$ were used, because smaller mussels were difficult to handle and arrange into patches. Sparse and clumped patches were made from similar proportions of different-sized mussels.
Experimental patches were constructed on concrete plates measuring $15 \times 15 \mathrm{~cm}$ and $1.2 \mathrm{~cm}$ thick. Each plate was first covered by a rigid plastic mesh, with a grid-size of $1.5 \times 1.5 \mathrm{~cm}$, to which the dead or artificial mussels were attached. This mesh was also put on the plates with live mussels. For the clumped treatment, patches of live mussels were constructed by tightly packing mussels in a single layer with the umbo at the base of a $13.5 \times 13.5 \times 9 \mathrm{~cm}$ plastic container. The mussels were then left in running seawater in an aquarium for up to $3 \mathrm{~d}$ and allowed to attach to one another by their byssal threads to form patches. The mussels were then carefully removed from their containers and placed onto plates with pre-drilled holes for attachment. For sparse treatments, live mussels had to be kept separate, to prevent them from moving to form a clump. A layer of thin nylon mesh, $1.5 \times 1.5 \mathrm{~cm}$, was placed over the mussels and sewn to the underlying rigid mesh using fine nylon line. This fine nylon mesh was therefore also used to attach all other experimental patches to the concrete plates. It was assumed that the grid of the nylon mesh was large enough to allow organisms to colonise the patches without impediment.

Patches of dead mussels were constructed using the shells of mussels. Each shell was filled with silicon, and several threads of nylon fishing line were attached to the umbo of the dead mussel to mimic byssal threads. Patches of artificial mussels were made using silicon moulds of different-sized mussels, obtained from the shells of dead mussels. The moulds were then filled with black dyed resin. Artificial byssal threads were made by adding several threads of nylon fishing line to the umbo of each mould before it dried. After $48 \mathrm{~h}$, when the silicon was dry, the mussels were tied to the rigid plastic mesh. The plates were then left in running seawater for up to $3 \mathrm{~d}$ before they were deployed in the field. To test for any effect of the mesh, mesh was also attached to patches of naturally occurring live mussels in the field (a procedural control), which were all clumped, because when the experiment was set up, no natural sparse patches were found.

To attach the concrete plates with minimal damage to the seawalls, 4 large stainless steel meshes (grid size $4.5 \times 4.5 \mathrm{~cm}$ ) were attached to the walls using dynabolts (9 $\mathrm{cm}$ long and $0.8 \mathrm{~cm}$ thick) and washers. On 17 March 2004, 3 plates of each of the 6 treatments (live, dead or artificial mussels arranged in sparse or clumped patches) were attached in randomly chosen positions to each of the 4 steel meshes using cable ties (i.e. 12 replicates per treatment).

Sampling. Samples were collected after 5 (17 August) and 9 (17 December) mo. These periods were long enough to ensure that relatively diverse assemblages would develop, but not so long that experimental treatments would be altered by settling mussels. Six repli- 
cates were collected at random from those available after $5 \mathrm{mo}$, except for dead sparse patches, where only 5 were available. At 9 mo, 5 remaining replicates of each treatment were available, except live clumped patches $(n=4)$. Prior to analyses, to balance the data, each missing replicate was replaced by the means of the other replicates in that treatment. This has no effect on means or variances of the samples (Underwood 1981). At each time, the mussels and associated fauna were sampled using $10 \mathrm{~cm}$ diameter cores (i.e. smaller than the size of the patch), which prevented mobile animals from escaping. Mussels within the core were removed into a bag in the field using a paint scraper. All samples were preserved in $7 \%$ formalin in seawater until sorted.

To estimate cover of sessile species on the mussel shells, the mussels were removed from the sample and divided into size classes. For each size, a maximum of 3 mussels was haphazardly selected to measure the percentage cover of all taxa on the shells. Cover was calculated from quadrats of $1 \times 4 \mathrm{~cm}$ placed to sample 8 points on each shell. For mussels in the 1-1.95, 2-2.95 and 3-3.95 cm size classes, 1 quadrat was used for each valve. For mussels in the 4-4.95 and 5-6 cm size classes, 2 quadrats were used on each valve. Organisms not included in the quadrats but present on the valves were given a value of 0.5 and added to the total. The total value was then converted to percentage cover per mussel. To calculate the mean percentage cover on each experimental plate, the mean cover on each size class was calculated. These values were weighted by the number of mussels in each size class and converted to an average measure per plate.

To count the numbers of organisms living in the spaces among the mussels, the remaining sample was sieved using a $500 \mu \mathrm{m}$ mesh, and all animals were sorted, identified and counted under a dissecting microscope. Different taxonomic resolutions (e.g. phylum, class, order and genus) were used to identify different types of organisms because of the lack of available taxonomic keys for some taxa and difficulties in identifying many of the sparse sessile taxa. Previous work has shown similar patterns of distribution of these assemblages among different mussel beds when different (or mixed) levels of taxonomic resolution are used (People 2006).

\section{RESULTS}

\section{Assemblages on mussel shells}

After 5 mo, 31 taxa were found on the shells of the mussels. Spirorbid and serpulid polychaetes and barnacles accounted for 20, 10 and $19 \%$, respectively, of the area of shells covered by organisms.

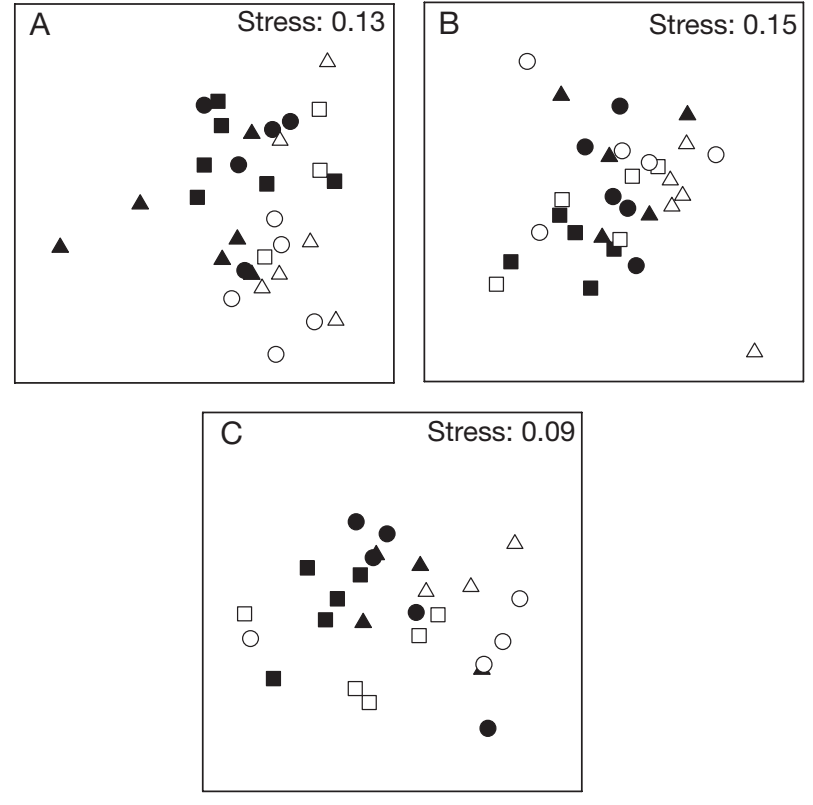

Fig. 1. nMDS plots of the assemblages living on (A) mussel shells of mixed sizes after $5 \mathrm{mo}$, (B) mussel shells of mixed sizes after $9 \mathrm{mo}$, and (C) only on small mussel shells after 9 mo. Beds were made from artificial $(\square, \square)$, dead $(\bullet, 0)$ or live $(\boldsymbol{\Lambda}, \Delta)$ mussels arranged in sparse $(\boldsymbol{\square}, \bullet, \mathbf{\Lambda})$ or clumped $(\square, \bigcirc$, $\Delta$ ) configurations (replicates with zero cover omitted from plot)

This assemblage was compared among treatments using PERMANOVA (multivariate analyses of variance; Anderson 2001) of Bray-Curtis dissimilarities (Bray \& Curtis 1957) calculated from untransformed data (mean percentage cover per taxon for each replicate). Factors were clumped/sparse (fixed), orthogonal to live/dead/artificial mussels (fixed). Each time was analysed separately. Significance of F-ratios was determined from 999 randomisations of the raw data (Anderson 2001).

Assemblages in sparse mussel patches differed significantly from those in clumped mussel patches $\left(F_{1,30}=2.70, \mathrm{p}=0.006\right.$; Fig. $\left.1 \mathrm{~A}\right)$, although there were no differences among live, dead and artificial mussels $\left(F_{2,30}=1.09, \mathrm{p}=0.33\right)$, nor a significant interaction between these factors $\left(F_{2,30}=1.35, \mathrm{p}=0.10\right)$.

When first examined, it became apparent that samples of small mussels might have been obscured by overlying large mussels in the clumped, but not the sparse, treatment. If assemblages on small mussels were affected by this, it could have confounded comparisons between sparse and clumped treatments. Accordingly, data were analysed separately for small mussels (1-2 cm and $2-3 \mathrm{~cm}$ shell length) and large mussels $(4-5 \mathrm{~cm}$ and 5-6 cm shell length). However, assemblages did not differ between sparse and clumped mussel beds (PERMANOVA; small mussels, $F_{1,30}=1.61, \mathrm{p}=0.11$; large 
mussels, $F_{1,30}=1.67, \mathrm{p}=0.08$ ) or among types of mussels (small mussels, $F_{2,30}=0.87, \mathrm{p}=0.56$; large mussels, $\left.F_{2,30}=0.53, \mathrm{p}=0.96\right)$, and there were no significant interactions (small mussels, $F_{2,30}=1.55, \mathrm{p}=0.08$; large mussels, $F_{2,30}=1.27, \mathrm{p}=0.21$ ).

There was considerable variability in assemblages on mussels of each size among the replicate patches within each of the treatments (mean Bray-Curtis dis-

Table 1. Mean Bray-Curtis dissimilarities (\%) for assemblages living on mussels, within (i.e. among replicates; $\mathrm{S}, \mathrm{C}$ ) and between sparse and clumped treatments (S vs. C), or within (A, D, L) and between artificial, dead or live treatments (A vs. D, A vs. L, D vs. L). S: sparse, C: clumped, A: artificial, D: dead, L: live mussels

\begin{tabular}{|c|c|c|c|c|c|c|c|c|c|}
\hline & \multicolumn{3}{|c|}{ Factor 1-Clumping } & \multicolumn{6}{|c|}{ Factor 2-State of mussels } \\
\hline & S & $\mathrm{C}$ & S vs. C & $\mathrm{A}$ & $\mathrm{D}$ & $\mathrm{L}$ & Avs. D & Avs. L & Dvs. L \\
\hline \multicolumn{10}{|l|}{$5 \mathrm{mo}$} \\
\hline All sizes & 87 & 87 & 91 & 88 & 88 & 90 & 87 & 93 & 87 \\
\hline Small mussels & 88 & 82 & 87 & 84 & 86 & 91 & 85 & 86 & 85 \\
\hline Large mussels & 83 & 85 & 86 & 84 & 89 & 88 & 83 & 85 & 85 \\
\hline \multicolumn{10}{|l|}{$9 \mathrm{mo}$} \\
\hline All sizes & 72 & 76 & 77 & 69 & 76 & 75 & 75 & 80 & 75 \\
\hline Small mussels & 79 & 88 & 88 & 79 & 89 & 87 & 87 & 88 & 84 \\
\hline Large mussels & 70 & 77 & 77 & 74 & 73 & 78 & 74 & 80 & 73 \\
\hline
\end{tabular}

similarities within treatments varied between 82 and $91 \%$ ), but no consistent differences between the relative amounts of variability between sparse and clumped treatments, nor among live, dead or artificial mussels for mussels of different sizes (Table 1).

The mean number of taxa per shell did not differ for either factor for all mussels, nor for large or small mussels separately (Table 2, Fig. 2A illustrates the pattern for all mussels). Only spirorbids and barnacles were widespread enough to be analysed as individual taxa (i.e. they were found in at least $50 \%$ of replicates). The percentage cover of barnacles was larger on sparse than on clumped mussels (Fig. 3A), although this difference was not significant when small and large mussels were analysed separately (Table 2). Spirobids did not differ among treatments (Table 2), except for large mussels, where sparse patches had a greater cover of spirorbids, with virtually none settled in the clumped patches (Fig. 3B).

Table 2. Analyses of number of taxa, cover of barnacles, mean cover of spirorbids after 5 mo ( $\mathrm{n}=6$ patches) and number of taxa, cover of barnacles, cover of spirorbids, cover of serpulids and cover of green algae after 9 mo ( $\mathrm{n}=5$ patches) for all mussels and, separately, for large and small mussels. SC: sparse vs. clumped, LDA: live vs. dead vs. artificial. ${ }^{*}: \mathrm{p}<0.05,{ }^{* *}: \mathrm{p}<0.01$

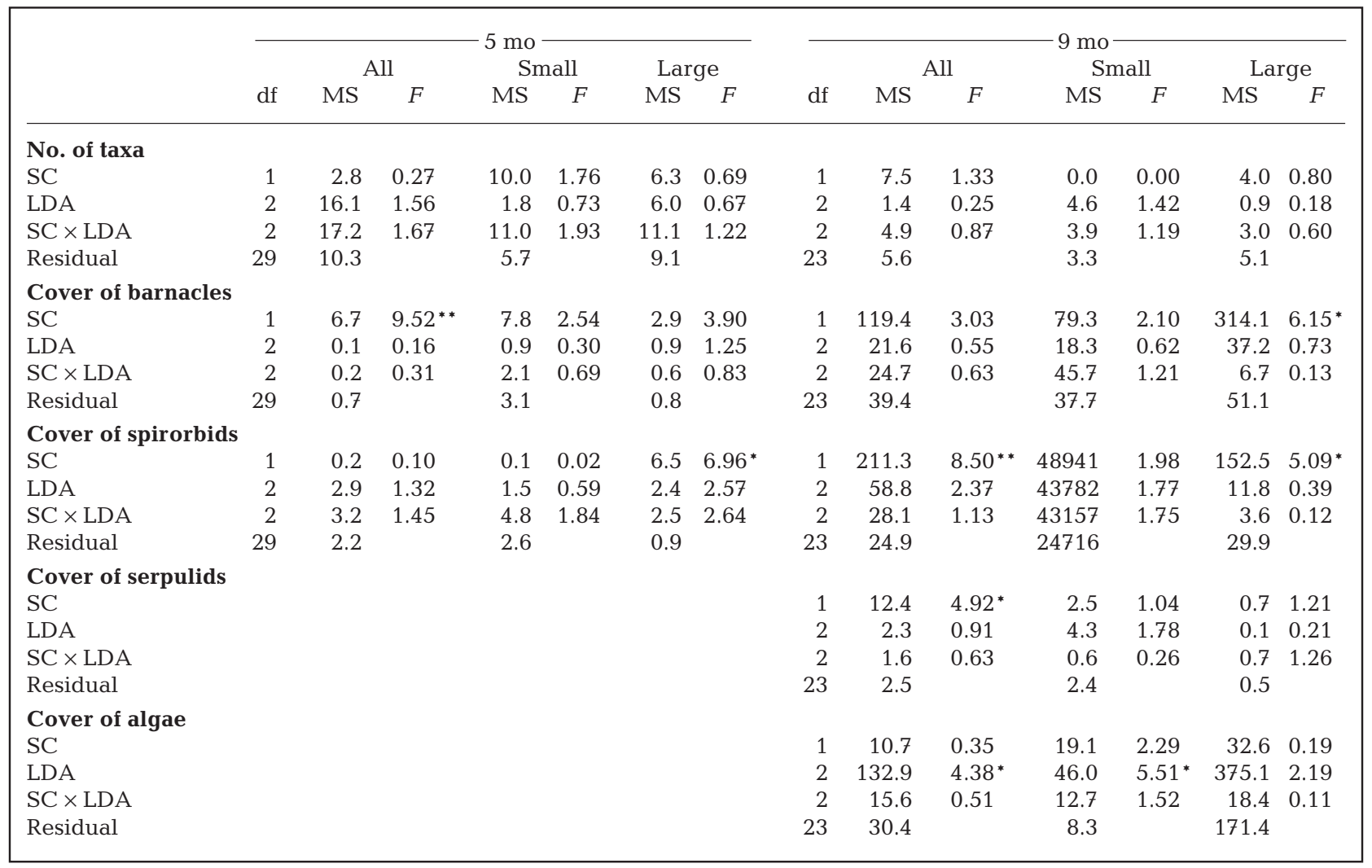



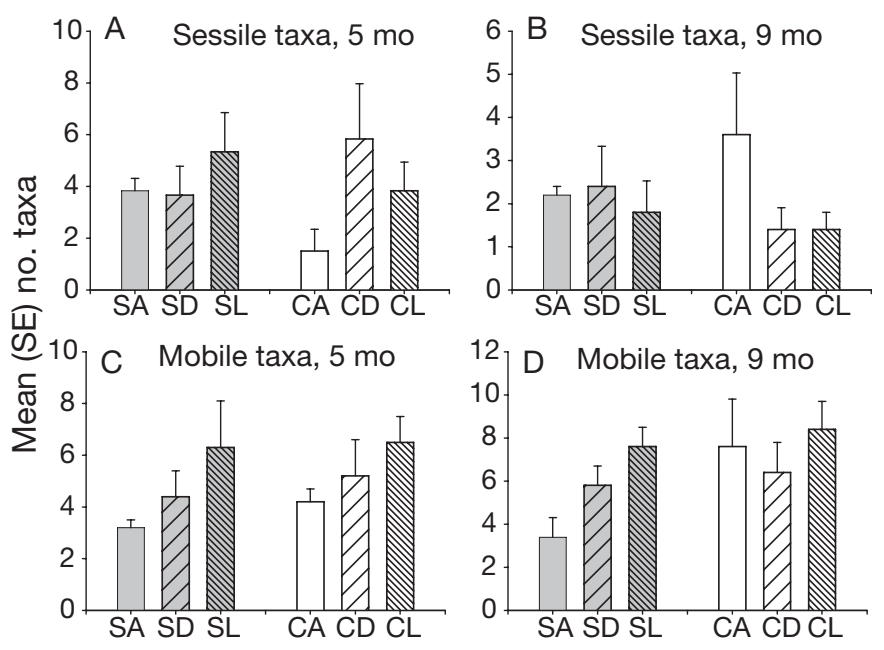

Fig. 2. Mean (SE) number of taxa after $(A, C) 5$ mo $(n=6)$ and $(\mathrm{B}, \mathrm{D}) 9 \mathrm{mo}(\mathrm{n}=5)$ for sessile taxa on shells $(\mathrm{A}, \mathrm{B})$ and mobile taxa living among the shells $(\mathrm{C}, \mathrm{D})$. SA: sparse artificial mussels, SD: sparse dead mussels, SL: sparse live mussels, CA: clumped artificial mussels, CD: clumped dead mussels, CL: clumped live mussels

After 9 mo, 21 taxa were found. The most common of these were spirorbids, barnacles and an unidentifiable green algal film $(28,25$ and $15 \%$ cover, respectively).

There were statistically significant differences between assemblages on mussels in sparse versus clumped treatments and among live, dead and artificial mussels (PERMANOVA; $F_{1,24}=2.05, \mathrm{p}=0.05$, $F_{2,24}=1.81, \mathrm{p}=0.03$, respectively), but a nonmetric multidimensional scaling (nMDS) plot showed considerable overlap among treatments (Fig. 1B). The assemblages in artificial patches differed from those on the live mussels $(p=0.01)$, with the assemblage on the dead mussels was intermediate between and not significantly different from either (dead:artificial, $\mathrm{p}=0.11$; dead:live, $p=0.69$ ). Assemblages in sparse patches also differed from those in clumped patches when large and small mussels were considered separately $\left(F_{1,24}=2.12, \mathrm{p}=0.008, F_{1,24}=2.35, \mathrm{p}=0.04\right.$, respectively), each of which showed clearer patterns than when size classes were combined (Fig. 1C shows the pattern for small mussels). There were no significant differences among assemblages on artificial, dead or live mussels for large or small mussels analysed separately $\left(F_{2,24}=1.40, \mathrm{p}=0.15, F_{2,24}=1.37, \mathrm{p}=0.14\right.$, respectively), nor any interaction between these factors $\left(F_{2,24}=0.81, \mathrm{p}=0.67, F_{2,24}=1.03, \mathrm{p}=0.44\right.$, respectively).

The mean dissimilarities among replicates after 9 mo were smaller than after $5 \mathrm{mo}$, although still relatively large (69 to $88 \%$; Table 1). For all comparisons, the dissimilarity among the sparse replicates was smaller than among the clumped replicates. The sensitivity of these analyses to differences in dispersions may have contributed to the significant difference between treatments in the analysis, explaining why it was not clearly illustrated in the nMDS plot.

The mean number of taxa per shell did not differ among any treatments (Table 2, Fig. 2B). Four taxa were widespread enough to be analysed separately (Table 2). Serpulid and spirorbid polychaetes had greater coverage in the clumped than in the sparse treatments when all mussels were considered and for spirorbids, when only large mussels were analysed (Table 2, Fig. 3C). This was opposite to the pattern shown by spirorbids after 5 mo. Barnacles showed a similar pattern at both times, with greater cover in the sparse treatment for large mussels (Table 2). There was greater cover of green filamentous algae on artificial than on dead or live mussels for all mussels and, separately, for small mussels (Fig. 3D).

\section{Assemblages of mobile animals}

After $5 \mathrm{mo}$, the mobile organisms living in the spaces among the mussels in a total set of samples comprised 5698 individuals from 27 taxa. These were mostly isopods (52\%) and amphipods (22\%).

These assemblages were analysed using 3 different measures. First, the raw data were analysed, i.e. the assemblage in each core. Second, the data were divided by the number of mussels in the patch (i.e. per mussel). Third, the raw data were standardised according to the number of individuals of the mobile
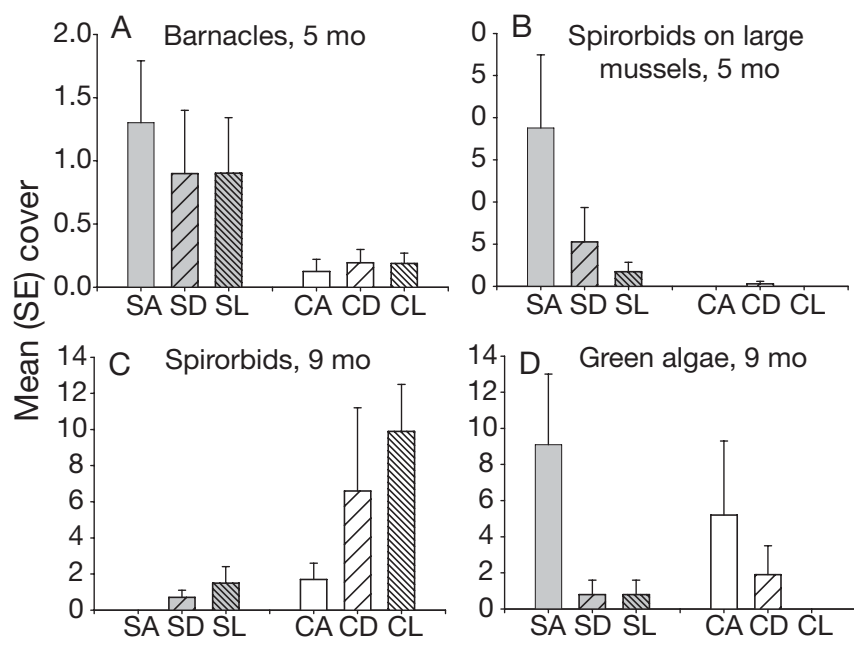

Fig. 3. Mean (SE) cover of (A) barnacles, (B) spirorbids (for large mussels) after 5 mo $(n=6)$; $(C)$ spirorbids, (D) green algae after 9 mo $(n=5)$. SA: sparse artificial mussels, SD: sparse dead mussels, SL: sparse live mussels, CA: clumped artificial mussels, CD: clumped dead mussels, CL: clumped live mussels 

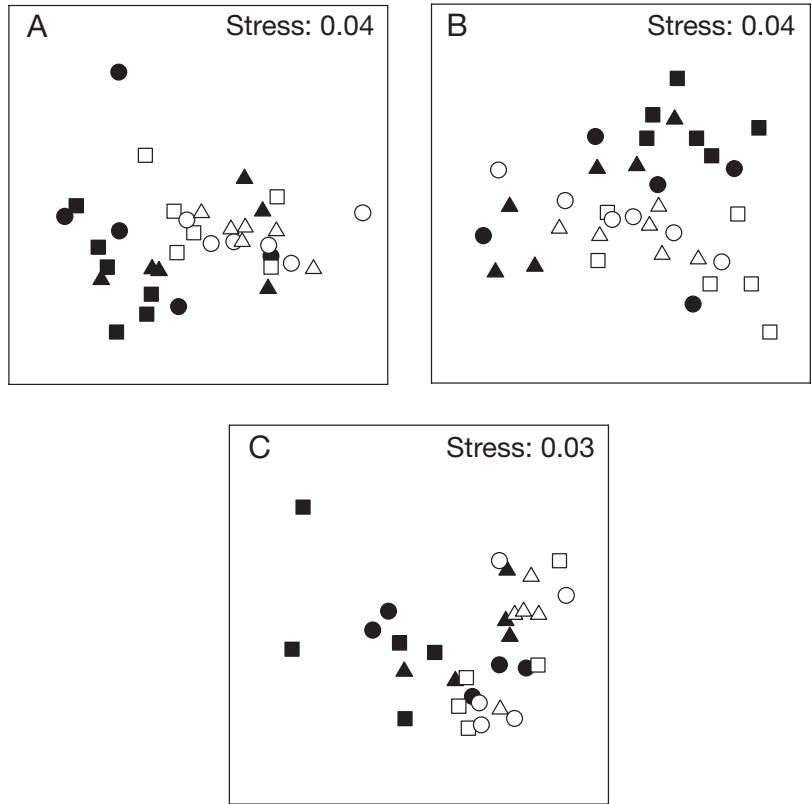

Fig. 4. nMDS plots of the assemblages of mobile animals living among the mussels (A) after $5 \mathrm{mo}$, (B) after 5 mo when data corrected for the number of mussels, and (C) after 9 mo. Beds were made from artificial $(\boldsymbol{\square}, \square)$, dead $(\bullet, 0)$ or live $(\boldsymbol{\Lambda}, \Delta)$ mussels arranged in sparse $(\boldsymbol{\square}, \bullet, \mathbf{\Lambda})$ or clumped $(\square, \bigcirc, \Delta)$ configurations

taxa to test hypotheses that treatments would change the relative abundances of the different taxa in the assemblage.

After $5 \mathrm{mo}$, the assemblage differed between the sparse and clumped treatments, for all analyses (PERMANOVA; raw data: $F_{1,30}=9.08, \mathrm{p}=0.002$; per mussel: $F_{1,30}=2.81, \mathrm{p}=0.03$; standardized: $F_{1,30}=9.27, \mathrm{p}=$ 0.001; illustrated in Fig. 4A \& B for raw data and per mussel, respectively). There was also an effect of the type of mussels (i.e. live, dead, artificial) for the raw data $\left(F_{2,30}=2.72, \mathrm{p}=\right.$ 0.01 ; Fig. 4A) and numbers per mussel $\left(F_{2,30}=2.63, \mathrm{p}=0.02\right.$; Fig. $\left.4 \mathrm{~B}\right)$, although pairwise comparisons could not find consistent differences. There was no effect of the type of mussels on the standardised data $\left(F_{2,30}=1.65, \mathrm{p}=\right.$ $0.10)$, and all interactions were nonsignificant ( $p>0.05)$.

Differences between sparse and clumped mussels are probably strongly influenced by the small dissimilarity values among the clumped replicates (i.e. replicate cores were very similar to each other compared to the cores of sparse mussels for the 3 sets of data; Table 3). These assem- blages showed less variability among replicates than did the sessile assemblages (compare Tables 1 \& 3). There was also more variability among replicates of the dead mussels, than either the artificial or live mussels, which showed no consistent patterns (Table 3). Standardising the data reduced variability among replicates within and between treatments, indicating that much of it was due to the numbers of individuals, rather than differences in the types of taxa.

Mean number of taxa per core did not differ between sparse and clumped treatments, nor among artificial, dead or live treatments (Table 4), although sparse and clumped mussels had more taxa in the live than in the dead mussels and least in the artificial mussels (Fig. 2C).

When abundances were analysed per core, amphipods and isopods (Fig. 5A) were more abundant in clumped treatments; gastropods and juvenile mussels showed no patterns (Table 4). For counts per mussel, isopods (Fig. 5B) and amphipods showed no differences among treatments, and gastropods were more common in the sparse treatments. Juvenile mussels were influenced by the type of mussel (Table 4, Fig. 5C), with greater abundance in the sparse live patches, although Student-Newman-Keuls (SNK) multiple comparisons failed to identify significant differences.

After 9 mo, 20044 individuals from 24 taxa were collected in all samples, the majority of which were small mussels ( $<1 \mathrm{~cm}$ in length; $38 \%$ ), amphipods (34\%) and isopods $(22 \%)$.

For the whole samples, assemblages differed between sparse and clumped treatments (PERMANOVA; $F_{1,24}=5.05, \mathrm{p}=0.005 ;$ Fig. $\left.4 \mathrm{C}\right)$. These differences were also significant when data were standardised $\left(F_{1,24}=\right.$ 6.96, $\mathrm{p}=0.02)$ and per mussel $\left(F_{1,24}=2.59, \mathrm{p}=0.05\right)$. Differences among types of mussels were also signifi-
Table 3. Mean Bray-Curtis dissimilarities (\%) for assemblages living among mussels, within (i.e. among replicates) and between sparse and clumped treatments, or within and between artificial, dead or live treatments. S: sparse, C: clumped, A: artificial, D: dead, L: live mussels; data are per core, corrected for the number of mussels or standardised by the number of individuals (details in text)

\begin{tabular}{|c|c|c|c|c|c|c|c|c|c|}
\hline & \multicolumn{3}{|c|}{ Factor 1-Clumping } & \multicolumn{6}{|c|}{ Factor 2-State of mussels } \\
\hline & $\mathrm{S}$ & $\mathrm{C}$ & S vs. C & A & $\mathrm{D}$ & $\mathrm{L}$ & Avs. D & Avs. L & Dvs. L \\
\hline \multicolumn{10}{|l|}{$5 \mathrm{mo}$} \\
\hline Per core & 57 & 43 & 62 & 50 & 66 & 46 & 61 & 55 & 66 \\
\hline Per mussel & 57 & 44 & 55 & 48 & 59 & 46 & 56 & 54 & 51 \\
\hline Standardised & 35 & 17 & 36 & 32 & 36 & 24 & 34 & 29 & 31 \\
\hline \multicolumn{10}{|l|}{$9 \mathrm{mo}$} \\
\hline Per core & 71 & 52 & 69 & 76 & 64 & 48 & 72 & 72 & 57 \\
\hline Per mussel & 70 & 53 & 65 & 68 & 64 & 43 & 69 & 58 & 71 \\
\hline Standardised & 41 & 39 & 45 & 44 & 39 & 32 & 45 & 49 & 39 \\
\hline
\end{tabular}


Table 4. Analyses of number of taxa, abundance of isopods, amphipods, gastropods, and juvenile mussels after 5 mo ( $\mathrm{n}=6$ patches) or after 9 mo ( $n=5$ patches) for the entire core and corrected by the number of mussels in the core; SC: sparse vs. clumped; LDA: live vs. dead vs. artificial. ${ }^{*}: \mathrm{p}<0.05,{ }^{* *}: \mathrm{p}<0.01$

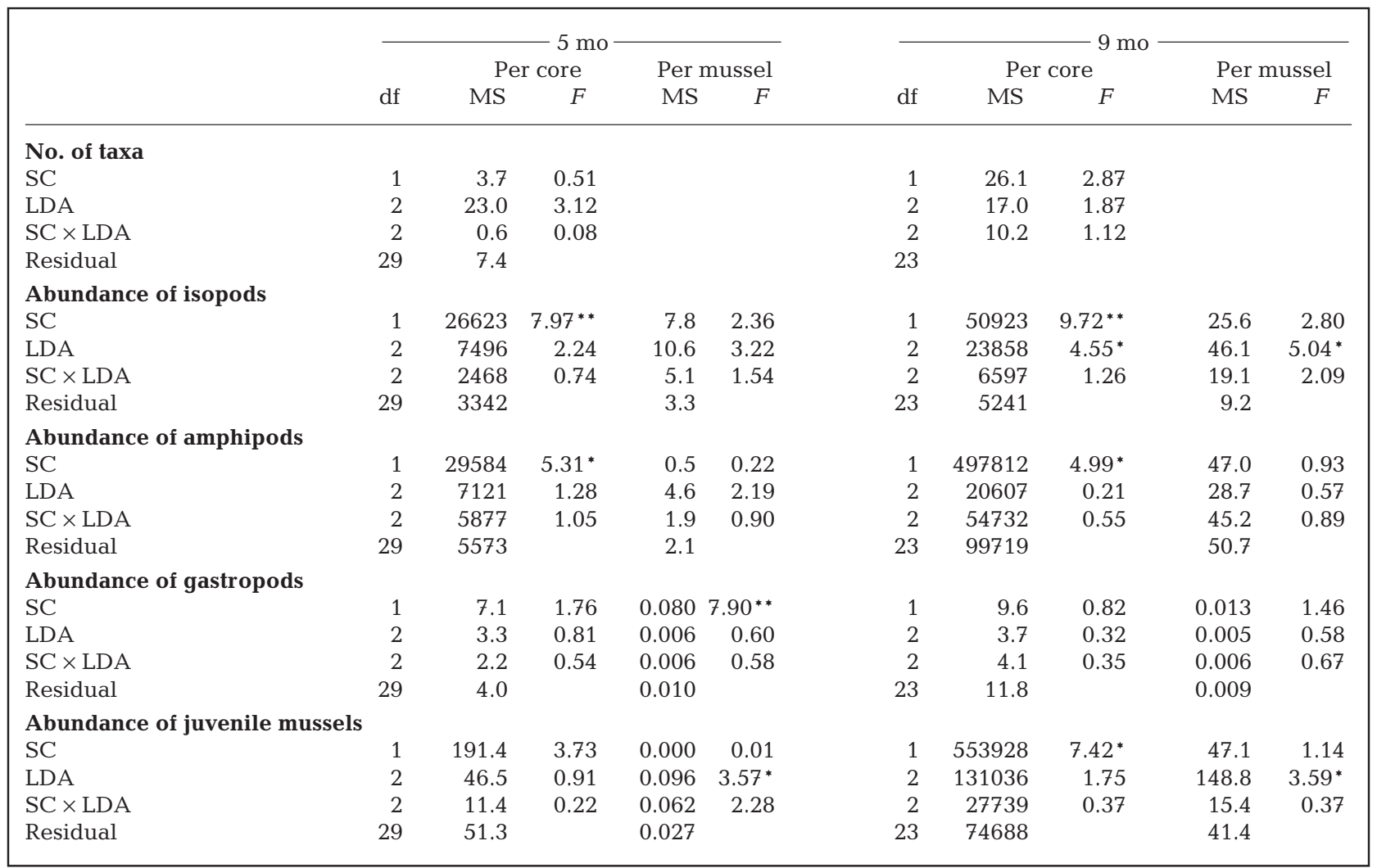

cant (PERMANOVA; $F_{2,24}=2.08, \mathrm{p}=0.05, F_{2,24}=2.76$, $\mathrm{p}=0.01, F_{2,24}=4.07, \mathrm{p}=0.02$, for data per core, per mussel and standardised, respectively). In no case, however, could pair-wise comparisons identify differences among these treatments. All interactions were non-significant ( $\mathrm{p}>0.05)$.

The amounts of variation among replicates were similar to those shown after 5 mo, i.e. clumped replicates were more similar to each other than were sparse replicates, and standardisation reduced variability among replicates in all treatments (Table 3).

The number of species did not differ between sparse and clumped treatments, nor among types of mussels (Table 4, Fig. 2D). When species were analysed separately, isopods, amphipods and juvenile mussels showed an effect of clumping (Table 4), with all 3 taxa significantly more abundant in clumped treatments (amphipods shown in Fig. 5D). Isopods also showed an effect of the type of mussels (Table 4), although SNK tests failed to identify these differences. However, they were more abundant in the living and least abundant in the artificial patches. Gastropods showed no effect of either treatment. Differences between sparse and clumped patches disappeared when data were analysed per mussel (Table 4, Fig. 5E). Although there were more isopods and juvenile mussels per mussel in the live mussel treatments (Table 4), these differences were not significant using SNK tests.

\section{Comparisons to controls and natural mussel beds}

When the organisms in the experimental patches of live clumped mussels were compared to those in the natural beds and in the procedural control treatment, there were no significant differences after 5 mo (PERMANOVA $; F_{2,12}=1.46, \mathrm{p}=0.07 ; F_{2,12}=2.00, \mathrm{p}=0.07$ for the sessile and mobile assemblage, respectively). These differences, as shown by the p-values, were marginal, but differences could not be identified by pairwise comparisons, so the interpretation as non-significant is appropriate. After $9 \mathrm{mo}$, the sessile assemblages differed among treatments $\left(F_{2,12}=1.72, \mathrm{p}=\right.$ $0.03)$, but again pairwise comparisons could not identify differences among treatments. The mobile assemblage living among the constructed patches of mussels differed significantly from those in natural mussels and in the procedural control $\left(F_{2,12}=4.72, \mathrm{p}=0.01\right)$, but this 


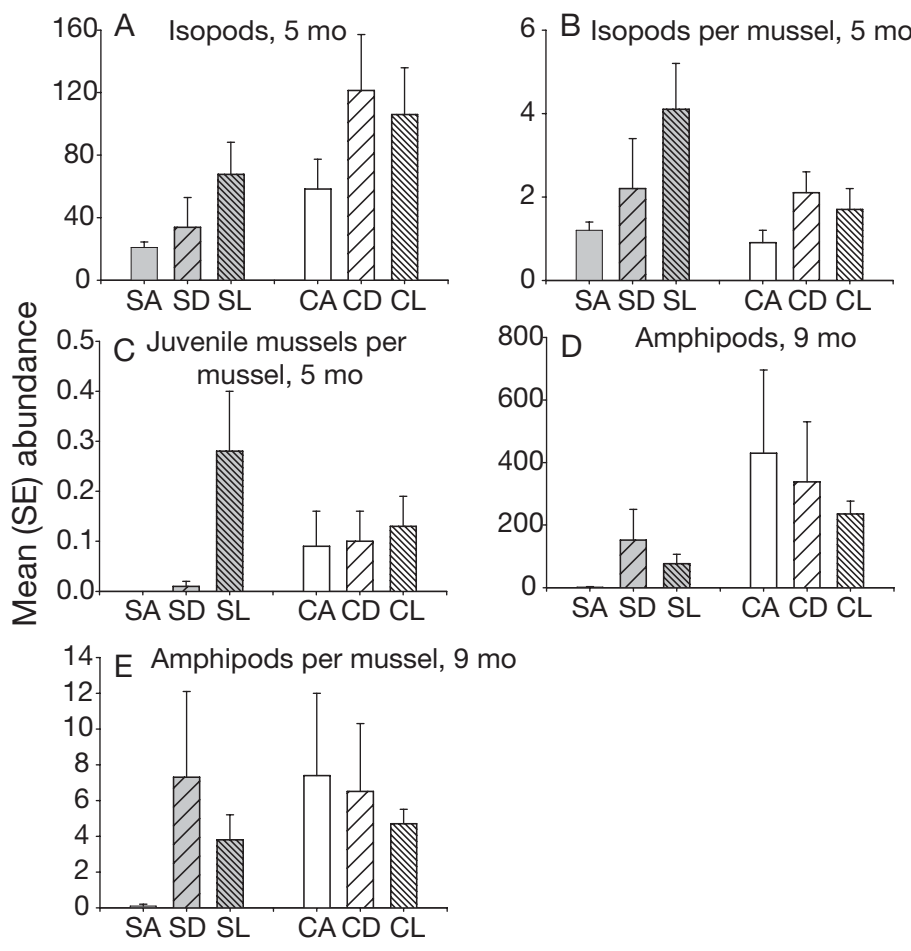

Fig. 5. Mean (SE) abundance of (A) isopods, (B) isopods per adult mussel, $(\mathrm{C})$ juvenile mussels per adult mussel after 5 mo $(\mathrm{n}=6)$; (D) amphipods, (E) amphipods per mussel after 9 mo $(n=5)$. SA: sparse artificial mussels, SD: sparse dead mussels, SL: sparse live mussels, CA: clumped artificial mussels, CD: clumped dead mussels, CL: clumped live mussels

difference disappeared when amphipods and isopods (the most abundant taxa) were removed from the analysis $\left(F_{2,12}=0.93, \mathrm{p}=0.60\right)$. There were more isopods and amphipods in the experimental patches (mean $\pm \mathrm{SE}=229 \pm 25$ and $188 \pm 62$, respectively) than in the undisturbed assemblage $(38 \pm 7$ and $82 \pm 18$, respectively) or procedural controls (52 \pm 13 and $100 \pm$ 21 , respectively).

\section{DISCUSSION}

Two components of the habitat provided by mussels were examined. First was the effect of having live mussels, dead mussel shells or a physical mimic of the physical structure alone on colonising assemblages. Second was the effect of clumping of the mussels or mimics. Clumping is often associated with changes in the structure of a mussel bed, such as the number of layers of mussels (Tsuchiya \& Nishihira 1986). In these experiments, the mussels were confined to a single layer, so density affected proximity of mussels, rather than layering. This was designed to alter complexity of habitat (i.e. the numbers of structural units, sensu
McCoy \& Bell 1991). Increased structural complexity facilitates settlement of many invertebrates (Dean 1981, Rule \& Smith 2005) and appears to be a general response in aquatic systems (Crooks \& Khim 1999). However, it is not general across all taxa. Thus, Dean (1981) used various structures to mimic different sessile invertebrates and showed that these structures enhanced settlement of mussels and tunicates, but not of barnacles or serpulid polychaetes.

After $5 \mathrm{mo}$, the sessile taxa clearly differed between sparse and clumped patches. This was mainly due to greater cover of spirorbids and barnacles on sparse than on clumped mussels, although cover of all taxa was very small. Barnacles readily settle on cleared spaces (Minchinton \& Scheibling 1993), and recruitment of spirorbids is enhanced by shade (James \& Underwood 1994, Glasby 1999). It was expected that the surfaces of the shells of the clumped mussels were more shaded by nearby mussels than were surfaces of sparse mussels, but it is possible that all surfaces were shaded on the vertical seawall. When data were separated for large and small mussels, there were no differences in assemblages, which was contrary to the hypothesis proposed. Many of the samples had no or very few organisms, so these data were dominated by zeroes or very small numbers.

After 9 mo, there was greater cover by many taxa. Assemblages differed between sparse and clumped treatments. At this time, serpulids and spirorbids were more abundant in clumped than on sparse treatments, as might be expected if they recruited to shaded surfaces (Glasby 1999). Barnacles were more abundant on sparse shells, although not significantly so.

The mobile assemblages also responded to the number of mussels, but only at the scale of a whole patch. Therefore, more mussels led to greater abundances of a range of taxa, but when the data were corrected for the number of mussels in the sample, these differences disappeared (although they were still relatively large after $9 \mathrm{mo}$ ). This indicates a direct effect of the number of mussels on the assemblage living among, rather than on, the mussel shells. The effect of increasing the number of shells in the clump did not, however, have a similar relative effect on all taxa in the assemblage. When data were standardised for the total number of individuals in the assemblages, relative abundances of taxa in the sparse treatment differed from those in the clumped treatment. These differences may have been influenced by differences in dispersion of the data within treatments, which confounds differences among centroids in multivariate data-sets (Anderson 2001). There was smaller variability among the replicates of the sparse treatment than the clumped treatment and, for many comparisons, as much or more variability among clumped replicates as shown between treatments. 
The most motile and abundant taxa (amphipods and isopods) were more abundant in the clumped treatment, possibly due to the increase in sheltered microhabitats among dense clumps of mussels. Amphipods increase densities on substrata densely colonised by zebra mussels, which is a direct response to complexity of the substratum (Ricciardi et al. 1997). Less mobile animals, such as gastropods, which were present in much smaller numbers, did not show a significant effect of complexity. When the data were corrected for the number of mussels, the more mobile taxa showed no differences, and gastropods were more abundant in the sparse treatment.

Recruitment of mussels was also greater into the clumped patches, which could be due to recruits from outside the patches recruiting more into dense patches, or recruits from breeding adults inside the patches remaining within patches. The former explanation is most likely, because larvae of mussels generally disperse widely (Suchanek 1985) and larvae of many invertebrates settle gregariously (Jeffery 2000), and the differences shown here remained significant when corrected for the number of adult mussels.

Whether the mussels were live, dead or artificial had much smaller effects on the sessile and mobile assemblages than the amount of clumping, and effects were similar for clumped and sparse mussels (interactions were generally non-significant). The sessile assemblage did not differ among any treatments, indicating that shells of live or dead mussels were no less attractive as settlement surfaces than were resin mimics. The only taxon that showed significant differences was the cover of ephemeral green algae, which occupied more space on artificial mussels than on the shells of live or dead mussels.

Although it was expected that taxa would accumulate over time, the numbers of sessile and mobile taxa were, in fact, slightly smaller after 9 than after 5 mo of sampling, although the mean percentage cover increased slightly. The sessile taxa were approximately $50 \%$ filamentous, encrusting or foliose algae and $50 \%$ animals, including polychaetes, bryozoans, ascidians and barnacles. Most of the cover was made up of few taxa, predominantly encrusting tubeworms and a fine film of ephemeral green algae. Although this assemblage was relatively diverse over all patches, it was also very patchy, with generally $<5$ taxa core $^{-1}$ (which contained approximately 15 and 60 mussels in the cores of the sparse and clumped treatments, respectively). Nevertheless, the sessile assemblage was similar between the experimental mussels that had been cleared of all attached organisms before deployment and natural mussel beds that had been present in the study site for many months prior to the study. Therefore, these experimental patches accumu- lated a natural cover of algae and sessile animals during the experiment.

Colonisation and development of the mobile assemblage was also expected to be completed within 5 mo because of the rate at which similar assemblages colonise other habitat-mimics (Gee \& Warwick 1996, Rule \& Smith 2005, Underwood \& Chapman 2006). Our results showed no differences in assemblages among natural and experimental patches of mussels after $5 \mathrm{mo}$, and, after $9 \mathrm{mo}$, differences were due to larger numbers of isopods and amphipods in the constructed patches. Although the numbers of mussels in the clumped experimental treatments were most similar to those in natural beds, the numbers of isopods and amphipods in the constructed sparse patches were most similar to those in natural beds. This may have been influenced by the fact that the constructed habitats formed small discrete patches, whereas the natural habitats were sampled from larger patches of more continuous habitat. Small or isolated patches of habitat may enhance local densities (Virnstein \& Curran 1986) because individuals 'crowd' into the limited availability of space. Overall, however, the similarity in the sessile and mobile assemblages indicated that these constructed units were appropriate to test hypotheses about the physical or biological effects of mussels on each of these assemblages of invertebrates.

Our results contrast with some other studies. For example, barnacles attached to living mussels grew faster than those on empty shells, perhaps due to feeding currents created by the mussels (Laihonen \& Furman 1986). Fouling assemblages, which include most of the taxa that recruited to these mussel patches, settle readily onto different surfaces, including artificial structures (Sutherland 1980). Hence, the use of fouling plates is widespread in the study of these assemblages (e.g. Dean 1981, Glasby 1999). Chapman \& Clynick (2006) showed that similar assemblages developed on natural surfaces and 3 types of artificial surfaces in nearby subtidal sites. Many taxa in that study were similar to those colonising mussel shells in our study.

In addition to providing diverse microhabitats for mobile animals, the surface of the shells can provide substrata for bacteria and microalgae (Tsuchiya \& Nishihira 1985), which could, in turn, provide food for motile taxa. The limpet Ferrissia rivularis was more abundant on zebra mussels than on surrounding areas, where it grazed on a film of diatoms (Ricciardi et al. 1997). The zebra mussel Dreissena polymorpha rapidly transforms the epilithic communities into assemblages dominated by small zebra mussels, amphipods, chironomids and small gastropods. An experiment using artificial substrata showed that the abundance of macro-invertebrates was enhanced by the formation of an interstitial shell matrix that was thought to provide 
a refuge, trap sediment and increase habitat complexity (Ricciardi et al. 1997). This contrasts markedly with our study, possibly because mussel beds were placed on vertical seawalls, which provided most of the intertidal hard substrata in the study site. Abundances of most taxa, therefore, did not show significant differences among treatments, or differences were not consistent between the clumped and sparse patches. Thus, isopods tended to be more abundant on live mussels when patches were sparse, but on live and dead mussels when patches were clumped (although differences were not significant). Other taxa similarly showed no or very variable patterns.

This study showed that for Mytilus galloprovincialis on seawalls in Sydney Harbour, the physical structure of the mussel beds is the main determinant of associated assemblages living on or among the mussels. Apart from the cover of green algae, which was greatest on artificial surfaces, and of spirorbids, which was greater on live shells (only after $9 \mathrm{mo}$ ), there were no consistent differences among types of patches. Artificial substrata have been shown to be important in programmes monitoring biodiversity because they are inexpensive to deploy and provide an identical, replicable habitat in different places (Gee \& Warwick 1996). Typically, artificial substrata on intertidal rocky substrata include panels (Dean 1981), dead shells (Ricciardi et al. 1997), pot scourers (Menge et al. 1994) or algal mimics (Norderhaug et al. 2002). Our experiments indicate that the repertoire of techniques can be extended to include resin mimics of mussel beds, which appropriately sample 2 assemblages of invertebrates living in these habitats.

Acknowledgements. This study was funded by the Australian Research Council through its Special Research Centre Programme and the University of Sydney. M.G.P. was also funded by an Unesco-LÓreal Fellowship for Women in Science. Thanks to A. Boden, S. Gartenstein and A. Grigaliunas for assistance in the field and numerous research support staff in the Centre for assistance in the laboratory. S. Brillant and P. Range offered helpful comments on the results, and 3 anonymous referees offered helpful comments on an earlier version of this paper.

\section{LITERATURE CITED}

Anderson MJ (2001) A new method for non-parametric multivariate analysis of variance. Austral Ecol 26:32-46

Bray JR, Curtis JT (1957) An ordination of the upland forest communities of Southern Wisconsin. Ecol Monogr 27: 325-349

Chapman MG, Clynick BG (2006) Experiments testing the use of waste material in estuaries as habitat for subtidal organisms. J Exp Mar Biol Ecol 338:164-178

Chapman MG, People J, Blockley D (2005) Intertidal assemblages associated with natural Corallina turf and invasive mussel beds on seawalls. Biodivers Conserv 14:1761-1776
Crooks JA, Khim HS (1999) Architectural vs. biological effects of a habitat-altering, exotic mussel, Musculista senhousia. J Exp Mar Biol Ecol 240:53-75

Dean TA (1981) Structural aspects of sessile invertebrates as organizing forces in an estuarine fouling community. J Exp Mar Biol Ecol 53:163-180

Gee JM, Warwick RM (1996) A study of global biodiversity patterns in the marine motile fauna of hard substrata. J Mar Biol Assoc UK 76:177-184

Gibbons MJ (1988) The impact of sediment accumulations, relative habitat complexity and evaluation of rocky shore meiofauna. J Exp Mar Biol Ecol 122:225-241

Glasby TM (1999) Effects of shading on subtidal epibiotic assemblages. J Exp Mar Biol Ecol 234:275-290

Gwyther J, Fairweather PG (2002) Colonisation by epibionts and meiofauna of real and mimic pneumatophores in a cool temperate mangrove habitat. Mar Ecol Prog Ser 229: 137-149

Iwasaki K (1995) Comparison of mussel bed community between two intertidal mytilids Septifier virgatus and Hormomya mutabilis. Mar Biol 123:109-119

James RL, Underwood AJ (1994) Influence of colour of substratum on recruitment of spirorbid tubeworms to different types of intertidal boulders. J Exp Mar Biol Ecol 181: 105-115

Jaramillo E, Bertran C, Bravo A (1992) Community structure of the subtidal macroinfauna in an estuarine mussel bed in southern Chile. PSZN I: Mar Ecol 13:317-331

Jeffery CJ (2000) Settlement in different-sized patches by the gregarious intertidal barnacle Chamaesipho tasmanica Foster and Anderson in New South Wales. J Exp Mar Biol Ecol 252:15-26

Kautsky N, Evans S (1987) Role of biodeposition by Mytilus edulis in the circulation of matter and nutrients in a Baltic coastal ecosystem. Mar Ecol Prog Ser 38:201-212

Kelaher BP (2002) Influence of physical characteristics of coralline turf on associated macrofaunal assemblages. Mar Ecol Prog Ser 232:141-148

Khaitov VM, Fokin MV, Nicolaeva AM (1999) Structures of communities associated with dense assemblages of the tube-dwelling polychaete Polydora quadrilobata Jacobi (Spionidae) in the White Sea. Hydrobiologia 393:221-226

Laihonen P, Furman ER (1986) The site of settlement indicates commensalisms between bluemussel and its epibiont. Oecologia 71:38-40

McCoy ED, Bell SS (1991) Habitat structure: the evolution and diversification of a complex topic. In: Bell SS, McCoy ED, Mushinsky HR (eds) Habitat structure: the physical arrangement of objects in space. Chapman and Hall, New York, p 3-27

Menge BA, Berlow EL, Blanchette CA, Navarette SA, Yamada SB (1994) The keystone species concept: variation in interaction strength in a rocky intertidal habitat. Ecol Monogr 64:249-286

Minchinton TE, Scheibling RE (1993) Variations in sampling procedure and frequency affect estimates of recruitment of barnacles. Mar Ecol Prog Ser 99:83-88

Norderhaug KM, Christie H, Rinde E (2002) Colonisation of kelp imitations by epiphyte and holdfast fauna: a study of mobility patterns. Mar Biol 141:965-973

People J (2006) Mussel beds on different types of structures support different macroinvertebrate assemblages. Austral Ecol 31:271-281

Reimer AA (1976) Succession of invertebrates in vacant tests of Tetraclita panamensis. Mar Biol 35:239-252

Ricciardi A, Whoriskey FG, Rasmussen JB (1997) The role of the zebra mussel (Dreissena polymorpha) in structuring 
macroinvertebrate communities on hard substrata. Can J Fish Aquat Sci 54:2596-2608

Rule MJ, Smith SDA (2005) Spatial variation in the recruitment of benthic assemblages to artificial substrata. Mar Ecol Prog Ser 290:67-78

Seed R, Suchanek TH (1992) Population and community ecology of Mytilus. In: Gosling EM (ed) The mussel Mytilus: ecology, physiology, genetics and culture. Elsevier Press, Amsterdam, p 87-169

Smith SDA, Rule MJ (2002) Artificial substrata in a shallow sublittoral habitat: do they adequately represent natural habitats or the local species pool? J Exp Mar Biol Ecol 277: 25-42

Stewart TW, Miner JG, Lowe RL (1998) Macroinvertebrate communities on hard substrates in western Lake Erie: structuring effects of Dreissena. J Gt Lakes Res 24: 868-879

Suchanek TH (1985) Mussels and their role in structuring rocky shore communities. In: Moore PG, Seed R (eds) The ecology of rocky coasts. Hodder \& Stoughton, London, p 70-96

Sutherland JP (1980) The fouling community at Beaufort,

Editorial responsibility: Roger Hughes (Contributing Editor), Bangor, UK
North Carolina: a study in stability. Am Nat 118:500-519 Tsuchiya M, Nishihira M (1985) Islands of Mytilus as a habitat for small intertidal animals: effect of island size on community structure. Mar Ecol Prog Ser 25:71-81

Tsuchiya M, Nishihira M (1986) Islands of Mytilus edulis as a habitat for small intertidal animals: effect of Mytilus age structure on the species composition of the associated fauna and community organization. Mar Ecol Prog Ser 31: 171-178

Underwood AJ (1981) Techniques of analysis of variance in experimental marine biology and ecology. Annu Rev Oceanogr Mar Biol 19:513-603

Underwood AJ, Chapman MG (2006) Early development of subtidal macrofaunal assemblages: relationships to period and timing of colonization. J Exp Mar Biol Ecol 330:221-233

Virnstein RW, Curran MC (1986) Colonization of artificial seagrass versus time and distance from source. Mar Ecol Prog Ser 29:279-288

Wisenden PA, Bailey RC (1995) Development of macroinvertebrate community structure associated with zebra mussel (Dreissena polymorpha) colonization of artificial substrates. Can J Zool 73:1438-1443

Submitted: December 20, 2006; Accepted: March 30, 2007 Proofs received from author(s): August 14, 2007 